\title{
Trends and Gaps in National Blood Transfusion Services - 14 Sub-Saharan African Countries, 2014-2016
}

\begin{abstract}
Udhayashankar Kanagasabai, MD²,2; Michelle S. Chevalier, MD²; Bakary Drammeh, DrPH²; Fatima D. Mili, MD, PhD²; Michael L. Qualls, MPH²; Naomi Bock, MD²; Irene Benech, MD²; Lisa J. Nelson, MD³; George Alemnji, PhD ${ }^{4}$; D. Heather Watts, MD ${ }^{4}$; Daniel Kimani, MD; Dejana Selenic, MD ${ }^{2}$
\end{abstract}

Ensuring availability of safe blood products through recruitment of voluntary, nonremunerated, blood donors (VNRDs) and prevention of transfusion-transmissible infections (TTIs), including human immunodeficiency virus (HIV), hepatitis B virus (HBV), hepatitis $\mathrm{C}$ virus (HCV), and syphilis, is important for public health $(1,2)$. During 2004-2016, the U.S. President's Emergency Plan for AIDS Relief (PEPFAR) provided approximately $\$ 468$ million in financial support and technical assistance* to 14 sub-Saharan African countries ${ }^{\dagger}$ with high HIV prevalence to strengthen national blood transfusion services (NBTSs) ${ }^{\S}$ and improve blood safety and availability. CDC analyzed these countries' 2014-2016 blood safety surveillance data to update previous reports $(1,2)$ and summarize achievements and programmatic gaps as some NBTSs begin to transition funding and technical support from PEPFAR to local ministries of health (MOHs) $(2,3)$. Despite a $60 \%$ increase in blood supply since 2004 and steady declines in HIV prevalence (to $<1 \%$ among blood donors in seven of the 14 countries), HIV prevalence among blood donors still remains higher than that recommended by the World Health Organization (WHO) (4). PEPFAR support has contributed to significant reductions in HIV prevalence among blood donors in the majority of PEPFAR-supported countries, and linking donors who screen HIV-positive to confirmatory testing and indicated treatment, as well as further reducing TTIs, remains a public health priority (5).

In 2016, WHO Global Status Report on Blood Safety and Availability reported that 5.6 million units of blood (4\% of the global supply) were collected in Africa; 38 African countries collected $<10$ whole-blood donations per 1,000 population, the WHO-recommended target (1). To meet demand, countries often rely on family or replacement donors who donate blood

\footnotetext{
*Blood Safety programs are funded through the Human Movement Blood Laboratories budget code.

†Côte d'Ivoire, Ethiopia, Ghana, Kenya, Lesotho, Mozambique, Nigeria, Rwanda, South Africa, Swaziland, Tanzania, Uganda, Zambia, and Zimbabwe. A full list of countries receiving PEPFAR support is available at https://www. pepfar.gov.

$\$$ National blood transfusion services refers to those government or nongovernmental organizations with a legal mandate to collect, test, process, and distribute blood and blood components within a given country, or the legal authority to oversee or regulate the collection, testing, processing, and distribution of blood and blood components by other entities within that country.

' https://www.who.int/bloodsafety/global_database/en/.
}

for a family member or friend; however, such donations carry a higher risk for TTIs (6). Since 2004, PEPFAR support has helped establish national blood policies, improved blood donor screening, increased recruitment and reliance on VNRDs for national supplies, and strengthened laboratory infrastructure, accreditation, information systems, and continuous quality improvement programs (4).

During 2014-2016, NBTSs in the 14 PEPFAR-supported sub-Saharan African countries used a standardized data collection tool to report the total number of blood units collected; the percentage of donated units that screened positive for HIV and other TTIs; the percentage of screen-positive donors who were notified of their result; and the status of financial support transition from PEPFAR to MOHs. MOH funding to support blood safety activities at the local NBTS was self-reported to the PEPFAR and CDC-supported WHO Global Database on Blood Safety. The numbers of whole blood units collected per 1,000 population per year were calculated using national census estimates or United Nations population projections. ${ }^{* *}$

During 2004-2016, overall total annual blood collections in PEPFAR-supported countries increased 60\%, from 1,469,561 units in 2004 to 2,352,905 units in 2016, although collection rates remain below WHO recommendations (1) in all countries except South Africa and Swaziland (Table 1). From 2014 to 2016, the number of units collected per 1,000 population decreased in five countries (Kenya, Lesotho, Nigeria, Swaziland, and Zambia); however, during this period, eight countries reported collecting $100 \%$ of their national blood supply from VNRDs. The largest increase in VNRD donations (40\%) occurred in Ethiopia (from 70\% in 2014 to $98 \%$ in 2016); however, declines in VNRD donations in Lesotho (18\%, from $96 \%$ to $79 \%)$ and Tanzania $(11 \%$, from $89 \%$ to $79 \%)$ also occurred.

In all 14 countries, most blood donors were men $(65 \%$ in 2014 and $86 \%$ in 2016); however, from 2014 to 2016, the number of female blood donors aged 20-24 years increased approximately thirtyfold, from 4,424 in 2014 to 146,571 in 2016. The largest increase in male donors (201\%) occurred among persons aged $30-34$ years, from 45,725 in 2014 to 137,596 in 2016.

\footnotetext{
** Africa Society for Blood Transfusion accreditation lasts for 2 years; Namibia was accredited in 2012.
} 
TABLE 1. Number of blood units collected by U.S. President's Emergency Plan for AIDS Relief (PEPFAR)-supported blood transfusion services, number of blood units from voluntary nonremunerated donors (VNRDs), and blood units collected per 1,000 population, by country 14 PEPFAR-supported countries, 2004 and 2014-2016

\begin{tabular}{|c|c|c|c|c|c|c|c|c|c|c|c|c|}
\hline \multirow[b]{2}{*}{ Country } & \multicolumn{3}{|c|}{2004} & \multicolumn{3}{|c|}{2014} & \multicolumn{3}{|c|}{2015} & \multicolumn{3}{|c|}{2016} \\
\hline & $\begin{array}{c}\text { No. } \\
\text { collected }\end{array}$ & $\%$ VNRD & $\begin{array}{l}\text { No. per } 1,000 \\
\text { population }\end{array}$ & $\begin{array}{c}\text { No. } \\
\text { collected }\end{array}$ & $\%$ VNRD & $\begin{array}{c}\text { No. per } 1,000 \\
\text { population }\end{array}$ & $\begin{array}{c}\text { No. } \\
\text { collected }\end{array}$ & $\%$ VNRD & $\begin{array}{c}\text { No. per } 1,000 \\
\text { population }\end{array}$ & $\begin{array}{l}\text { No. } \\
\text { collected }\end{array}$ & $\%$ VNRD & $\begin{array}{c}\text { No. per } 1,000 \\
\text { population }\end{array}$ \\
\hline Côte d'Ivoire & 77,972 & 100 & 3.4 & 143,691 & 100 & 6.3 & 155,534 & 100 & 6.8 & 168,025 & 100 & 7.4 \\
\hline Ethiopia & 43,247 & 59 & 0.4 & 87,685 & 70 & 0.8 & 140,061 & 97 & 1.4 & 173,923 & 98 & 1.7 \\
\hline Ghana & 165,426 & 41 & 6.0 & 150,322 & 30 & 5.4 & 155,250 & 34 & 5.6 & 160,624 & 36 & 5.8 \\
\hline Kenya & 18,440 & 100 & 0.4 & 183,475 & 100 & 3.9 & 155,081 & 100 & 3.3 & 167,100 & 100 & 3.6 \\
\hline Lesotho & 3,000 & 95 & 1.4 & 8,373 & 96 & 3.9 & 7,879 & 97 & 3.7 & 5,008 & 79 & 2.3 \\
\hline Mozambique* & 67,105 & 58 & 3.4 & 121,091 & 39 & 4.3 & 126,068 & 42 & 4.5 & 131,231 & 45 & 4.6 \\
\hline Nigeria $^{\dagger}$ & 1,266 & 100 & $<0.1$ & 48,908 & 91 & 0.2 & 66,614 & 82 & 0.3 & 51,329 & 84 & 0.2 \\
\hline Rwanda & 28,777 & 100 & 2.4 & 42,789 & 100 & 3.6 & 53,436 & 100 & 4.6 & 61,768 & 100 & 5.3 \\
\hline South Africa & 709,324 & 100 & 13.0 & 803,818 & 100 & 14.7 & 828,689 & 100 & 15.2 & 810,895 & 100 & 14.8 \\
\hline Swaziland & 7,060 & 100 & 5.4 & 14,727 & 100 & 11.3 & 13,752 & 100 & 10.5 & 13,687 & 100 & 10.5 \\
\hline Tanzania§ & 129,404 & 66 & 2.4 & 128,915 & 89 & 2.4 & 67,980 & 49 & 1.2 & 196,735 & 79 & 3.6 \\
\hline Uganda & 112,250 & 100 & 2.8 & 212,939 & 100 & 5.4 & 230,995 & 100 & 5.9 & 243,335 & 100 & 6.2 \\
\hline Zambia & 38,477 & 71 & 2.3 & 109,269 & 100 & 6.7 & 100,110 & 100 & 6.1 & 104,355 & 100 & 6.4 \\
\hline Zimbabwe & 67,813 & 100 & 4.3 & 58,603 & 100 & 3.7 & 59,767 & 100 & 3.8 & 64,890 & 100 & 4.1 \\
\hline Total & $1,469,561$ & - & 2.2 & $2,114,605$ & - & 3.4 & $2,161,216$ & - & 3.6 & $2,352,905$ & - & 3.8 \\
\hline
\end{tabular}

Source: 2004, 2014-2016 population data from the Joint United Nations Programme on HIV and AIDS. http://aidsinfo.unaids.org/.

Abbreviations: AIDS = acquired immunodeficiency syndrome; HIV = human immunodeficiency virus.

* 2004 data for Mozambique from https://www.cdc.gov/mmwr/volumes/65/wr/mm6505a4.htm.

† Nigeria and Tanzania did not have data for 2004; therefore, data for 2003 and 2005 were used.

During 2014-2016, the prevalence of whole blood units screening positive for HIV declined in 10 countries (range $=0.1-1.2$ percentage-point declines) but increased in Nigeria (by 0.1 percentage point), Rwanda (0.1) and Swaziland (1.2) (Table 2). The HIV screening prevalence among donated units in seven countries remains higher than the WHO target of $<1 \%$ (4). During 2014-2016, in nine countries with information on informing donors of HIV screening results, only $18.0 \%(2,971$ of 16,539 [2014]) to $27.6 \%$ (3,660 of 13,269 [2016]) of donors who screened HIV-positive were notified of their results (Figure). During this period, the total number of deferrals remained steady ( $>250,000$ units); however, deferrals attributable to high-risk behavior declined from 2014 to 2015 .

From 2014 to 2016, the prevalence of HBV, HCV, and syphilis reactivity in donated blood units decreased in six countries; decreases ranged from 0.1 percentage point (Tanzania) to 1.3 percentage points (Mozambique) (Table 2). The prevalence of TTIs in donated units increased in seven countries (Côte d'Ivoire, Ghana, Lesotho, Nigeria, Rwanda, South Africa, Swaziland, and Uganda) (Table 2). In 2016, the percentage of donated blood units that screened positive for all TTIs ranged from 0.7 (South Africa) to 14.6 (Nigeria).

As support for local blood safety programs transitioned to MOHs from PEPFAR, MOHs in Ethiopia, Swaziland, and Tanzania completely absorbed the cost of collecting and testing blood in 2016. Nine of 12 countries with available data report $\geq 50 \%$ of MOH support to the NBTS (Supplementary Table, https://stacks.cdc.gov/view/cdc/61188).

\section{Discussion}

Sub-Saharan African countries have improved access to safe and adequate blood supplies, but continued commitment and funding are required to maintain gains and achieve WHO targets. Although the number of blood units collected has increased since 2004, whole blood collections remain insufficient to meet national demand: 12 of 14 evaluated countries do not meet the WHO-recommended target (1). This shortfall especially affects women with pregnancy-related complications, trauma victims, and children with severe life-threatening malaria-related anemia ( 7 ).

Although most of the 14 PEPFAR-supported countries reported decreases in the percentage of collected blood units that screened positive for HIV since 2004, percentages remain significantly higher than the $0.003 \%$ reported by high-income countries (1). Seven countries have HIV screen-positive rates that exceed the WHO recommended target of $<1.0 \%$. Although HIV prevalence rates among blood donors have decreased, prevalences of other TTIs such as HBV, HCV, and syphilis increased in seven countries. To reduce the risk for TTIs in sub-Saharan Africa when PEPFAR support ends, $\mathrm{MOH}$ can participate in cross-sector collaborations to implement blood bank quality and safety accreditation standards through the African Society for Blood Transfusion (AfSBT) ${ }^{\dagger \dagger}$ or other international accrediting bodies and implement PEPFARsupported blood safety information systems. Recent data indicate that $50 \%$ of PEPFAR-supported countries still do

\footnotetext{
†† https://afsbt.org/.
} 
TABLE 2. Population prevalence of human immunodeficiency virus (HIV) infection among persons aged 15-49 years in the general population, percentage of collected blood units reactive for HIV, and percentage of collected blood units reactive for three transfusion-transmissible infections (TTIs) (hepatitis B virus [HBV], hepatitis C virus [HCV], and syphilis), by country - 14 U.S. President's Emergency Plan for AIDS Relief-supported countries, 2014-2016*

\begin{tabular}{|c|c|c|c|c|c|c|c|c|c|c|c|c|}
\hline \multirow[b]{4}{*}{ Country } & & & & \multicolumn{9}{|c|}{ Prevalence (\%) of TTIs in collected blood units } \\
\hline & & & & & & & & ther TTI & & & All TTIs & \\
\hline & \multicolumn{3}{|c|}{ HIV population prevalence (\%) } & \multicolumn{3}{|c|}{ HIV } & \multicolumn{3}{|c|}{ HBV, HCV, and syphilis } & \multicolumn{3}{|c|}{ HIV, HBV, HCV, and syphilis } \\
\hline & 2014 & 2015 & 2016 & 2014 & 2015 & 2016 & 2014 & 2015 & 2016 & 2014 & 2015 & 2016 \\
\hline Côte d'Ivoire & 3.0 & 2.8 & 2.7 & 0.3 & 0.04 & 0.2 & 8.6 & 9.0 & 8.9 & 9.0 & 9.0 & 9.1 \\
\hline Ethiopia & 1.1 & 1.1 & 0.9 & 2.1 & 1.2 & 1.1 & 4.4 & 4.6 & 4.2 & 5.2 & 5.1 & 4.5 \\
\hline Ghana & 1.7 & 1.6 & 1.6 & 0.7 & 0.5 & 0.3 & 9.7 & 7.1 & 11.6 & 11.8 & 8.3 & 12.7 \\
\hline Kenya & 5.7 & 5.6 & 5.4 & 0.6 & 0.8 & 0.6 & 2.8 & 4.3 & 2.5 & 3.5 & 5.2 & 3.2 \\
\hline Lesotho & 24.7 & 24.9 & 25 & 2.6 & 2.4 & 2.5 & 3.6 & 3.8 & 5.0 & 6.2 & 6.2 & 7.6 \\
\hline Mozambique & 13.0 & 12.7 & 12.3 & 5.2 & 4.8 & 4.0 & 8.2 & 8.8 & 6.9 & 13.4 & 13.6 & 11.0 \\
\hline Nigeria & 3.1 & 3.0 & 2.9 & 1.4 & 1.4 & 1.5 & 11.3 & 11.7 & 13.1 & 12.9 & 13.2 & 14.6 \\
\hline Rwanda & 3.2 & 3.2 & 3.1 & 0.1 & 0.1 & 0.2 & 2.6 & 2.7 & 3.4 & 2.8 & 2.9 & 3.6 \\
\hline South Africa & 18.8 & 18.9 & 18.9 & 0.2 & 0.2 & 0.1 & 0.3 & 0.3 & 0.5 & 0.5 & 0.5 & 0.7 \\
\hline Swaziland & 27.6 & 27.5 & 27.2 & 0.7 & 1.5 & 1.9 & 1.6 & 3.0 & 5.6 & 2.4 & 4.6 & 7.6 \\
\hline Tanzania & 6.9 & 6.7 & 6.5 & 1.4 & 1.5 & 1.3 & 7.7 & 14.3 & 7.6 & 9.2 & 10.8 & 8.9 \\
\hline Uganda & 5.0 & 4.8 & 4.7 & 0.9 & 0.6 & 0.6 & 3.4 & 4.2 & 3.8 & 4.3 & 4.8 & 4.4 \\
\hline Zambia & 12.7 & 12.6 & 12.4 & 3.4 & 2.9 & 2.9 & 8.1 & 7.1 & 7.0 & 11.6 & 10.1 & 10.0 \\
\hline Zimbabwe & 14.3 & 13.9 & 13.5 & 0.5 & 0.4 & 0.4 & 0.6 & 0.4 & 0.4 & 1.1 & 0.8 & 0.8 \\
\hline
\end{tabular}

Source: 2014-2016 from United Nations Development Program population estimates. http://hdr.undp.org/en/data\#.

Abbreviation: AIDS = acquired immunodeficiency syndrome.

* Self-reported data for 2014, 2015, and 2016.

not have a computerized information system for blood donor tracking and TTI testing. Since 2016, blood safety information systems have been implemented in three countries, with another two planned by 2019. To date, only four NBTSs in sub-Saharan Africa (Namibia [accredited in 2012], South Africa, Rwanda, and Tanzania) have achieved accreditation by an external body. Seven countries are currently in various stages of the accreditation process through AfSBT. Global CDC blood safety targets are that $50 \%$ of NBTS sites reach at least the first of three accreditation steps under AfSBT during the next $2-3$ years.

As countries move toward the United Nations 95-95-95 targets ( $95 \%$ of HIV infection diagnosed, $95 \%$ of infected persons receiving antiretroviral therapy [ART], and $95 \%$ of those on ART achieving viral suppression) for achieving epidemic control, increasing outreach to priority populations for testing and preventive services become increasingly important (8). Currently, no systems exist within these NBTSs to link persons determined to be ineligible for donation through behavioral risk screening to HIV testing and preventive services.

During 2014-2016, four NBTSs transitioned from PEPFAR to full $\mathrm{MOH}$ funding. An additional five countries received $\geq 50 \%$ of their funding from $\mathrm{MOH}$; two countries reported a decrease in $\mathrm{MOH}$ funding. As PEPFAR transitions occur, countries should consider prioritization of funding to their NBTS to sustain the gains achieved (9).

The findings of this report are subject to at least four limitations. First, blood unit collections described in this report only

\begin{abstract}
Summary
What is already known on this topic?

Since 2004, the U.S. President's Emergency Plan for AIDS Relief has improved blood availability and safety in 14 sub-Saharan African countries; however, the risk for human immunodeficiency virus (HIV) transmission via transfusion remains unacceptably high.

What is added by this report?

During 2014-2016, blood collections increased and donor HIV prevalence decreased in seven of the 14 countries, but systems to link HIV-positive and donors at high risk to testing and treatment are inadequate.

What are the implications for public health practice?

Sustained investments by ministries of health in continuous quality improvement, national blood transfusion services accreditation, linkage of HIV-positive and donors at risk to testing, care, and treatment, and blood safety information systems remain important components to ensure the viability of blood safety programs.
\end{abstract}

represent units collected by the NBTS, and do not account for units collected in the private sector or by nonnational blood transfusion services. Second, variations in testing capacity and assays used for laboratory screening (most NBTSs lack $\mathrm{HBV}$ and $\mathrm{HCV}$ confirmatory testing) might result in over- or underestimation of TTI prevalence rates among blood donors. Third, lack of information systems to link donors who screen HIV-positive to treatment services might result in inaccurate 
FIGURE. Total number* of blood units collected for all deferrals, ${ }^{\dagger}$ deferrals at high risk, ${ }^{\S, 9}$ human immunodeficiency virus (HIV)-positive donors, and HIV-positive donors notified of their HIV status, by year — nine U.S. President's Emergency Plan for AIDS Relief-supported countries, ${ }^{* *} 2014-2016^{\dagger \dagger}$

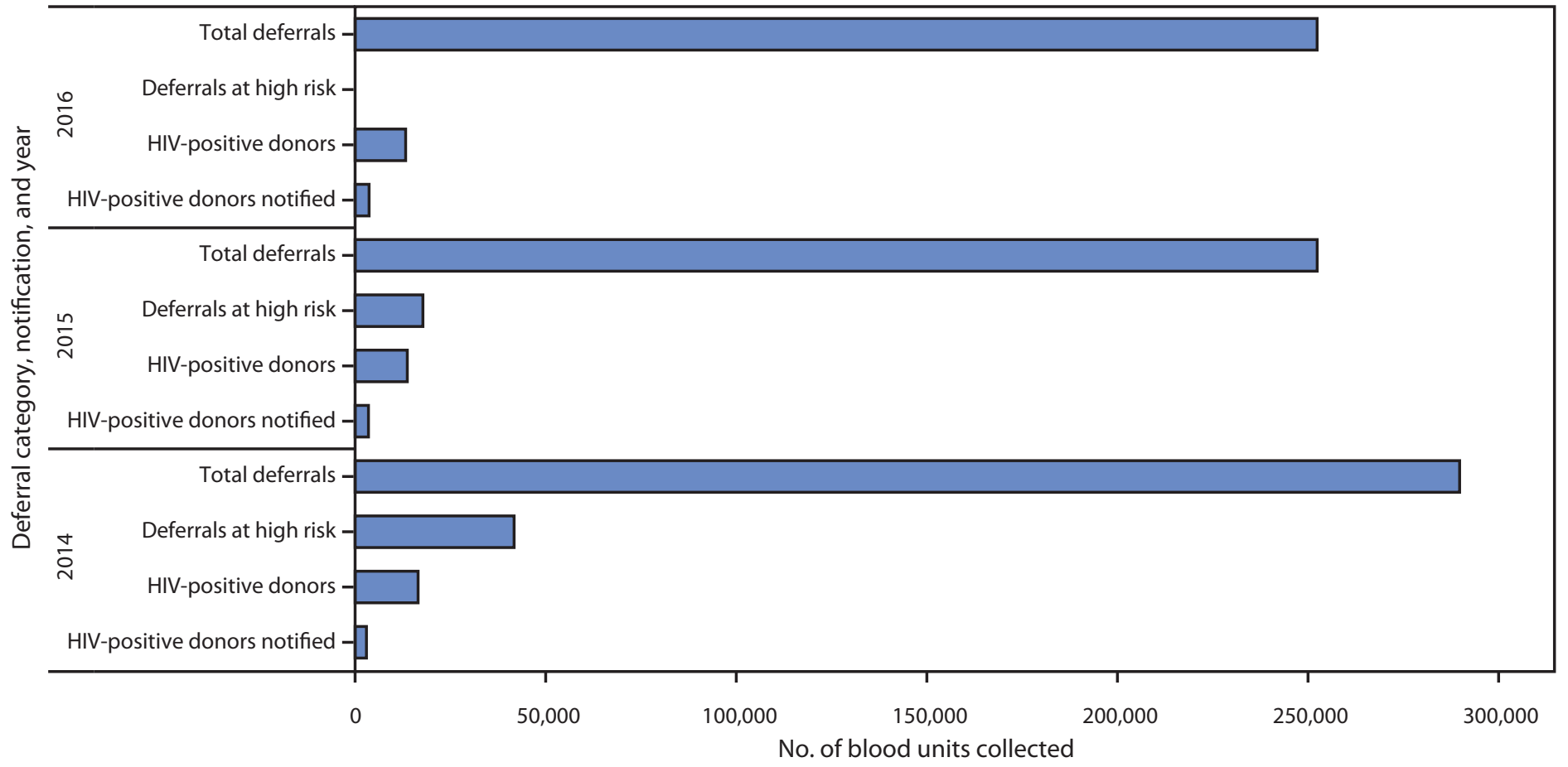

Abbreviation: AIDS = acquired immunodeficiency syndrome.

* Total number of blood units collected: 1,583,617 in 2014; 1,590,104 in 2015; and 1,771,798 in 2016.

† Deferrals are defined as donors who do not meet donor selection criteria after administration of a risk assessment questionnaire.

$\S$ Deferrals at high risk, classified based on seven categories of behavior; data for number of deferrals at high risk from Global Database for Blood Safety.

I Percentage of deferrals at high risk from total blood units collected: 2014, 14\%; 2015, 7\%; and 2016, data not available.

** Ethiopia, Kenya, Nigeria, Rwanda, South Africa, Swaziland, Tanzania, Uganda, and Zambia.

${ }^{++}$Number of deferrals at high risk for 2016 was not available.

estimations of the number of donors who are notified about their status. Finally, self-reported data from countries might result in inaccurate estimations.

A decade of PEPFAR support to NBTSs in 14 countries has led to increases in blood collections, fewer donors screening HIV-positive, and transition of support from PEPFAR to MOHs. However, gaps in linking deferred donors at high risk to HIV testing and prevention services, and in notifying HIVpositive donors of their status and linking them to confirmatory testing, care, and treatment underscore the need for enhanced focus on epidemic control, as well as innovative strategies to address donors who test positive for other TTIs. Ending reliance on unsafe blood donors requires continued investment in laboratory quality improvement, including increased engagement in external proficiency testing and increased use of highly sensitive assays at the NBTS and non-NBTS testing sites. Continued improvement of blood safety programs in subSaharan Africa will require sustained investments in continuous quality improvement, NBTS accreditation under AfSBT, linkage of deferred donors who report high risk behaviors and those who screen HIV-positive to HIV testing services and treatment, and stronger blood safety information systems. Strengthening health systems and developing local policy and sustainable financial resources are all important components to consider to ensure the future viability of blood safety programs.

\section{Acknowledgments}

Michael Melchior, CDC Ghana; Cathy Toroitch-Ruto, CDC Kenya; Andrew R. Pelletier, CDC Lesotho; Mukhtar L. Ahmed, CDC Nigeria; Judith Hedje, CDC Côte d'Ivoire; Leonardo Desousa, CDC Mozambique; Dan Gama, Ao Trong, CDC Swaziland; Amy Herman-Roloff, CDC South Africa; Peter J. Chimpo, CDC Zambia; John H. Rogers, CDC Zimbabwe.

Corresponding author: Udhayashankar Kanagasabai, nqy2@cdc.gov, 404-769-6027.

\footnotetext{
${ }^{1}$ Epidemic Intelligence Service, CDC; ${ }^{2}$ Division of Global HIV/AIDS and Tuberculosis, Center for Global Health, CDC; ${ }^{3} \mathrm{CDC}$ Uganda; ${ }^{4}$ Office of the Global AIDS coordinator and Health Diplomacy; ${ }^{5} \mathrm{CDC}$ Kenya.

All authors have completed and submitted the ICMJE form for disclosure of potential conflicts of interest. No potential conflicts of interest were disclosed.
} 


\section{References}

1. World Health Organization. Global status report on blood safety and availability. Geneva, Switzerland: World Health Organization; 2016. http:// apps.who.int/iris/bitstream/handle/10665/254987/9789241565431-eng.pdf

2. CDC. Progress toward strengthening blood transfusion services- 14 countries, 2003-2007. MMWR Morb Mortal Wkly Rep 2008;57:1273-7.

3. US President's Emergency Plan for AIDS Relief (PEPFAR). PEPFAR results \& funding. Washington, DC: US President's Emergency Plan for AIDS Relief; 2018. https://www.pepfar.gov/funding/index.htm

4. Chevalier MS, Kuehnert M, Basavaraju SV, Bjork A, Pitman JP. Progress toward strengthening national blood transfusion services- 14 countries, 2011-2014. MMWR Morb Mortal Wkly Rep 2016;65:115-9. https:// doi.org/10.15585/mmwr.mm6505a4

5. World Health Organization. Blood transfusion safety. Global database on blood safety. Geneva, Switzerland: World Health Organization; 2008 https://www.who.int/bloodsafety/global_database/en/
6. van Hulst M, Smit Sibinga CT, Postma MJ. Health economics of blood transfusion safety - focus on sub-Saharan Africa. Biologicals 2010;38:53-8. https://doi.org/10.1016/j.biologicals.2009.10.006

7. World Health Organization. Blood transfusion safety. Geneva, Switzerland: World Health Organization; 2008. https://www.who.int/ bloodsafety/en/

8. Joint United Nations Programme on HIV/AIDS. Fast-track ending the AIDS epidemic by 2030. Geneva, Switzerland: Joint United Nations Programme on HIV/AIDS; 2014: http://www.unaids.org/sites/default/ files/media_asset/JC2686_WAD2014report_en.pdf

9. Vogus A, GraffK. PEPFAR transitions: lessons learned through the experience of past donor transitions and applications for the Eastern Caribbean. Bethesda, MD: Health Finance and Governance and Strengthening Health Outcomes through the Private Sector Projects, Abt Associates Inc; 2014. https://www. hfgproject.org/wp-content/uploads/2015/01/PEPFAR-Transitions-PaperAbt-Assoc-Jan_5_2015-4.pdf 